\section{Seeing is believing as brain reveals its adaptability}

SIR - It is traditionally accepted that acquisition of vision must occur in the first year or two of life, before the critical period for vision has elapsed. We were fascinated, therefore, by your News Feature "Look and learn" (Nature 441, 271-272; 2006) reporting acquisition of competent vision in Pawan Sinha's patient following almost 30 years of functional blindness, particularly as we have observed a similar phenomenon in the more limited domain of stereo-blindness.

Although stereo-blindness is infinitely less disabling than total blindness, it too is generally considered to be incorrigible if not treated in early childhood. Yet we have recently followed a 50-year-old stereo-blind woman who, with proper ocular alignment, has been able to achieve full stereopsis, including the perception of random-dot stereograms, after many decades of stereoblindness (O. Sacks New Yorker 64-73; 19 June 2006).

A critical period for the development of many aspects of visual perception remains a valid concept, and every effort should be made towards early intervention when compromised vision is detected. Nonetheless, if there is any early vision at all — even such limited vision as Sinha's patient had, or the very small fusional area that severe esotropic strabismus may permit, as in our own patient - it seems that islands of cortical function may be established, which can be reactivated and enlarged even decades later, given the requisite optical or surgical help. In such a situation, there is apparently enough cortical plasticity still present in the adult brain to allow, in some people, a full visual recovery. Oliver Sacks*, Ralph M. Siegel†

*2 Horatio Street 3G, New York, New York 10014, USA

†Center for Molecular and Behavioral

Neuroscience, Rutgers University, New ark, New Jersey 07102, USA

\section{Discrete reminder about Weismann's discovery}

SIR — Like any other science, genetics cherishes its stories about its heroes ( ${ }^{\circ} \mathrm{Hard}$ to track" Nature 441, 400;2006). In his published papers (see www.mendelweb.org), and in his letters to Carl von Nägeli (C. Stern and E. R. Sherwood The Origin of Genetics; Freeman, 1966), Gregor Mendel makes no mention of discreteness; and he probably never thought about it.

Mendel was lucky that the discrete symbols of algebra agreed with the discrete units of inheritance. Mendel is the founder of genetics for discovering the algebraic laws of biological inheritance, not discreteness. It was Ronald A. Fisher (The Genetical Theory of Natural Selection; Clarendon, 1930) who put Mendel and discreteness on the same page, creating the modern myth by implication.

The discreteness of the modern gene was described by August Weismann as early as 1893, in his dassic book The Germ Plasm (Scribner's), which is still in print. In it, Weismann describes units of inheritance, or 'ids', as 'granular'. Fisher was aware of Weismann's ids (R. A. Fisher Science Progress 21, 159-160; July 1926), and probably wanted to shift credit to his fellow mathematician, Mendel.

In The Germ Plasm, Weismann also republishes a drawing by Theodor Boveri, a co-discoverer of meiosis, showing paired units of inheritance arranged in a double row, like beads on a string.

William L.Abler

Department of Geology, The Field Museum, 1400 South Lake Shore Drive, Chicago, Illinois 60605, USA

\section{Researchers frustrated by lack of input to NIH policy}

SIR - In the current discussion about the US National Institutes of Health (NIH), its director and its direction ${ }^{1-3}$, we have heard much about the fact that funding will probably not increase for the foreseeable future, and about the many challenges confronting the organization.

Clearly, where there is adversity, there is opportunity. Thus, one cannot help but agree with Michael Bishop and Harold Varmus that the way forward lies in "making common cause with the leadership of $\mathrm{NIH}^{\mathrm{m}}$ and joining forces. Unfortunately, an issue that has been overlooked is exactly how to make this happen.

Many NIH-funded investigators in the trenches' are very unhappy right now, not only because funding is tight, but also because they are frustrated by a lack of ready access to, or input in to, global funding decisions and important policies. I suspect that if there were more discussion about these critical issues, then investigators would be much more understanding and even at ease. Instead, it seems as though there is a wide communication gap between those who make decisions about funding (Congress and the NIH leadership) and those who do and direct so much of the research that the funding supports (typical scientists).

Many investigators are so busy with research, patient care and administrative duties that time for such exchange is limited. Nonetheless, both the NIH and the biomedical-research community would benefit from thoughtful, transparent discussion about biomedical research in the United States in a structured forum. It could even lead to productive action.

DonC. Rockey

University of Texas Southwestem Medical Center, 5323 Harry Hines Boulevard, Dallas, Texas

75390-8887, USA

1. Marks, A. R.J. Clin Invest. 116, 844(2006).

2. Science 312, $499(2006)$

3 Nature $441,17-19$ (2006)

\section{Public will fear biological accidents, not just attacks}

SIR - As one of the few Europeans who took part in the Synthetic Biology 2.0 conference in California in May, I read your Editorial "Policing ourselves" (Nature 441, $383 ; 2006$ ) and News story "Synthetic biologists try to calm fears" (Nature 441, $388-389 ; 2006)$ with great interest. The impression I received is that synthetic biologists are trying to alleviate public concerns over their research area - but will have serious difficulty in succeeding.

Most discussions in the field about selfregulation are focused on biosecurity that is, preventing new opportunities for bioterrorists - in an attempt to act proactively and prevent overly restrictive regulations being imposed by the authorities. But the concerns raised in the open letter from civil organizations including Greenpeace and Genewatch UK deal with the biosafety aspects: in other words, the uncertainties and unintentional consequences of synthetic-biology research, as opposed to its deliberate misuse. Although biosafety concerns were discussed at the conference, they are mainly unaddressed in the self-regulation attempt. Yet they will be increasingly significant as the syntheticbiology field develops, especially in Europe.

Synthetic biology shares many characteristics with other new technologies regarding public perception of novelty, uncertainty and controllability; we are all aware of the controversy in Europe over genetically modified crops. This time, we should be more far-sighted, and proactively address biosafety concerns as well as ethics, and intellectual-property rights as much as biosecurity. The Synthetic Biology 3.0 conference in Zurich next year will be a good opportunity.

Markus Schmidt

InternationalDialogue and Conflict Management, Abt-Karl Gasse 19/21, 1180 Vienna, Austria

\section{Correction}

The name of the co-author, John Lancaster, was accidentally left off the Correspondence letter" "Referee factor" would reward a vital contribution" (Nature 441, 812; 2006). 